\title{
On application of $X$-ray aproximation method for studying the substructure of sufficiently perfect samples
}

\author{
S.V.Malykhin ${ }^{1}$, I.E.Garkusha ${ }^{2}$, V.A.Makhlay $^{2}$, \\ S.V.Surovitsky ${ }^{1}$, M.V.Reshetnyak ${ }^{1}$, S.S.Borisova ${ }^{1}$ \\ ${ }^{1}$ National Technical University "Kharkiv Polytechnical Institute", \\ 2 Kyrpychova Str., 61002 Kharkiv, Ukraine \\ ${ }^{2}$ National Scientific Center "Kharkiv Physical and Technical Institute", \\ 1 Academicheskaya Str., 61108 Kharkiv, Ukraine
}

Received October 25, 2016

The technique of X-ray diffraction investigation of coherence length and micro-strain level using approximation of diffraction line profiles by Gaussian and Cauchy functions as well as by harmonic analysis has been worked out for tungsten samples with quite perfect structure. The importance of right choice of a standard for obtaining the reasonable measurement results has been demonstrated. For the first approximation the possibility to use the spectral line width for calculation of the reflection true (physical) broadening has been shown. The contributions of basic instrumental factors into the reflection geometric broadening were estimated.

Keywords: X-ray diffraction, coherence length, micro-strain, approximation method, physical broadening.

Отработана методика рентгенографического исследования размера областей когерентного рассеяния и величины микродеформаций путем аппроксимации профилей дифракционных линий функциями Гаусса, Коши, а также применением гармонического анализа для образцов вольфрама с достаточно совершенной структурой. Продемонстрирована важность правильного выбора эталона для получения разумных результатов измерений. Показано, что в первом приближении при расчёте истинного (физического) расширения допустимо использование теоретической спектральной ширины линий. Сделана оценка вклада в геометрическое расширение основных инструментальных факторов.

Про застосування способу апроксимації до вивчення субструктури достатньо досконалих зразків рентгенівським методом. С.В.Малихін, I.Є.Гаркуша, В.О.Махлай, С.В.Суровицький, М.В.Решетняк, С.С.Борисова.

Відпрацьовано методику рентгенографічного дослідження розміру областей когерентного розсіяння та величини деформацій шляхом апроксимації профілів дифракційних ліній функціями Гаусса, Коши, а також використанням гармонічного аналізу для зразків вольфраму з достатньо досконалою структурою. Продемонстровано важливість правильного вибору еталону для отримання розумних результатів вимірювань. Показано, що у першому наближенні при розрахунку істинного (фізичного) розширення $\epsilon$ допустимим використання теоретичної спектральної ширини лінії. Зроблено оцінку вкладу у геометричне розширення основних інструментальних факторів. 


\section{Introduction}

In physics of materials and physics of solids, one of actual problems of structure analysis is attestation of a sample structure state, namely, determination of the average coherence length (CL) $\langle L\rangle$ and average micro-strains $<\varepsilon>$. Usually, for determination of the sub-structure parameters either the approximation method or the harmonic analysis is applied [1-4]. Recently, the method of moments is also discussed [5]. These methods are quite tested and used for studying the strongly strained samples. These are based on the analysis of angle dependence of diffraction maxima broadening taking into account the geometric (instrumental) broadening. It is assumed that other causes of the physical broadening, such as packing defects [6] are absent. For estimation of the instrumental broadening, usually the measurements of a standard are used. For very strongly strained samples with coherence lengths $L<100 \mathrm{~nm}$, the absence of the standard does not result in any substantial error.

Technique difficulties appear under studying the sufficiently perfect samples which diffraction patterns showing $\mathrm{K}_{\alpha}$-doublet splitting already for diffraction medium angles. Such the case was observed, in particular, under studying $\mathrm{Al}$ and $\mathrm{Al}-\mathrm{Li}$ samples. In the samples strongly strained at cryogenic temperatures, as a result of dynamical recrystallization, the perfection of the structure was sharply increased as the deformation degree grew [7,8]. Similar problems are present when studying the radiation stability of both $\mathrm{Zr}$ and $\mathrm{Zr}-5 \% \mathrm{Nb}$ samples from TEE (thermo-emitted element) shells [9] and in researches of cracking the tungsten as a primary Plasma Facing Material (PFM) relevant to diverter of ITER (International Thermonuclear Experimental Reactor, Cadarache facility in Saint-Paulles-Durance, south of France ) fusion reactor $[10,11]$. When the diffraction maxima of the sample and the standard are close by widths at small angles, the obtained coherence length $L \approx 500-700 \mathrm{~nm}$ is found to be absurd. Sometimes, Hall plots get into the negative area that is principally impossible. According to [1], measurable by X-ray method maximum coherence length value should not exceed 250-300 nm which corresponds to the case when the minimum width of the diffraction maxima is equal to the line spectral width. As the problem of studying the sub-structure parameters and their evolution under the influence of different factors on sufficiently perfect samples occurs periodically, our aim was to work out a correct enough technique of corresponding X-ray diffraction (XRD) measurements.

\section{Experimental}

The technique task combines both the correct choice of a standard and the minimization of instrumental factors contributing into the geometric broadening of diffraction maxima. As the samples, the pure tungsten ones supplied by Plansee AG (Austria) have been used. They were prepared by different technologies. Once forged cylindrical specimens (set WJL) with a diameter of $12 \mathrm{~mm}$ and a height of $5 \mathrm{~mm}$ were prepared from a $1 \mathrm{~m}$ long rod (diameter of $12 \mathrm{~mm}$, the deformation axis along the rod) [12]. The grain orientation was parallel to the heat transfer direction. Double forged (DF series) targets were prepared by the following way [13]. These materials were sintered into a rod shape, thermo-mechanically deformed in the axial direction to obtain around blank with a height of $\sim 29 \mathrm{~mm}$ and a diameter of $\sim 160 \mathrm{~mm}$ and subsequently stress released at $1000^{\circ} \mathrm{C}$. As a result of the axial forging, the grains were heavily deformed to a disc-like shape perpendicular to the forging direction. Samples with dimensions $12 \times 12 \times 5 \mathrm{~mm}^{3}$ were cut with the disc-like grains oriented parallel to the loaded surface. A WKB series is double forged samples with sizes of $12 \times 12 \times 1 \mathrm{~mm}^{3}$. All the samples were polished to a mirror finish to obtain the undamaged well-defined starting state.

WJL and DF samples were prepared and delivered from Forschungszentrum Julich (Julich, Germany). WKB specimens were delivered from Max Planck Institute for Plasma Physics, (Garching, Germany). These were assumed to be different by structure state. Such kinds of tungsten materials are chosen as a reference of Plasma Facing Materials (PFC) for the diverter of the experimental fusion reactor ITER and for the first wall and the diverter of the next-step fusion reactor DEMO. Now the ITER project is at the stage of building. Nevertheless, the critical issue for the successful realization of this project is to predict structure and substructure changes in plasma-facing materials subjected by powerful heat plasma loads and intensive fluxes of particles relevant to the fusion reactor plasma. Tungsten is the priority PFC for 
the fusion reactor due to following advantages: high thermal conductivity, high temperature strength and stability, high recrystallization temperature and the high sputtering threshold for hydrogen. The main tungsten disadvantage is high brittleness. Nevertheless, the tungsten is a suitable object for experiments: it has a unique isotropy of elastic properties; therefore, it is possible to use it for calculations of all available X-ray diffraction maxima. Hall plots can be constructed by a lot of points, i.e. are most correct; additionally, it is possible to analyze the material for packing defects.

For determination of the geometric broadening, a specially annealed powder sample of the same material is usually used as a standard. In the present work, the materials used for this aim were: diamond powder, recrystallized polycrystalline Al, single crystalline mica - muscovite, and single crystalline mica - fluorinephlogopite. Firstly, it is necessary to plot the dependence of the peak broadening on the diffraction angle $2 \theta$ for a standard; then from this dependence, the geometric broadening for the standard should be determined for the diffraction angle range specific for tungsten.

The diffraction patterns were recorded using step by step $\theta-2 \theta$ scanning in the $\mathrm{Cu}$-anode radiation for samples and standards using the DRON-type X-ray diffractometer. The receiving slit size in front of the counter was from 0.25 to $0.05 \mathrm{~mm}$.

The treatment of the diffraction patterns and determination of integral widths of maxima were carried out using the "New_Profile 3.5" soft-ware with approximations of profiles by Cauchy or Gauss functions. The contributions of different factors of geometric broadening into the total broadening of a diffraction profile were estimated by calculation of function convolutions using the method of numerical simulation.

\section{Results and discussion}

\subsection{Choice of a standard}

In Fig. 1, the angle dependences are shown for line widths $B$ of $\mathrm{W}-\mathrm{K}_{\alpha 1}$ diffraction profiles for all reflections of one of tungsten samples (a), and for several standards (b). The line widths of conventional standards of diamond and aluminum (curve 1) are found to be comparable with the widths of the studied material at the diffraction
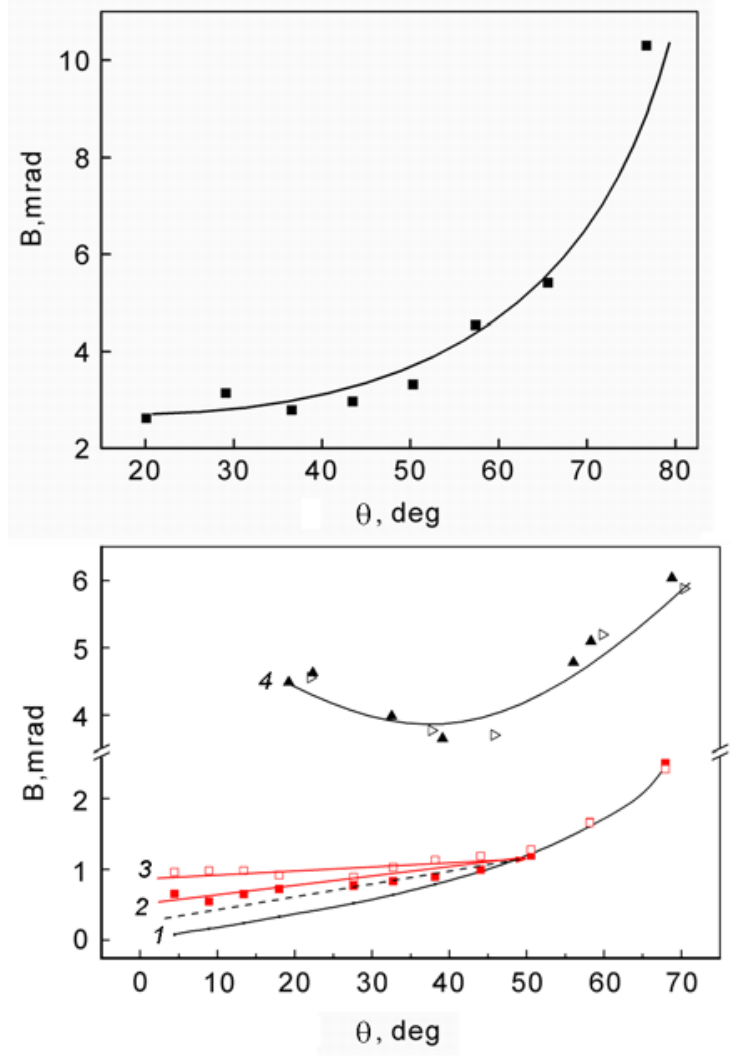

Fig. 1. Diffraction peak widths versus diffraction angle for aWKB30 tungsten sample (a) and for a series of standards (b): 1 aluminum (black triangles) and diamond (clear triangles); 2 - mica recorded with the slit $0.1 \mathrm{~mm} ; 3$ - mica recorded with the slit $0.05 \mathrm{~mm} ; 4$ - theoretical spectral line width.

angle $\theta \approx 70^{\circ}$ (Fig. 1). Moreover, for low angles the "standard" width is even larger than for the tungsten. Consequently, the recrystallized aluminum and the powder diamond can not be used as standards. Much smaller width is observed for mica samples, and in the range $\theta>45^{\circ}$ this coincides with the spectral width calculated according to the theory [1, 14]. At lower angles, the mica lines widths exceed the spectral one, and are found to be the more, the wider is the receiving slit in front of the counter. Calculations by the simulating method have shown that the convolution of the symmetric function corresponding to both the spectral line and the slit function taken from [15] transfers the line 4 in Fig. 2b into the dashed line position. After calculation of the convolution with the function accounting the projection of the tube focal spot, we obtain complete agreement with the curve 3 or 2 depending on the receiving slit function. Thus, the conclusion can be done that 
Table. Substructure parameters: coherence length $L$, micro-strains $\varepsilon$, and dislocation densities $\rho_{L}$ in walls and in crystallite bulk $\rho_{\varepsilon}$ calculated from X-ray diffraction line widths for different tungsten sample series

\begin{tabular}{|c|c|c|c|c|c||}
\hline \hline Sample number & Series & $L, \mathrm{~nm}$ & $\varepsilon \cdot 10^{3}$ & $\rho_{L}, 10^{10} \mathrm{~cm}^{-2}$ & $\rho_{\varepsilon}, 10^{10} \mathrm{~cm}^{-2}$ \\
\hline 1 & WKB42 & 49 & 1.1 & 12.0 & 5.0 \\
2 & W-coating/Cu & 57 & 1.7 & 9.2 & 1.5 \\
3 & WKB30 & 52 & - & 11.1 & - \\
$4 \mathrm{DF}$ & 54 & - & 10.3 & - & - \\
5 & WJL & 79 & 0.9 & 4.8 & 4.3 \\
6 & Irradiated coating & 80 & - & 4.7 & - \\
\hline
\end{tabular}

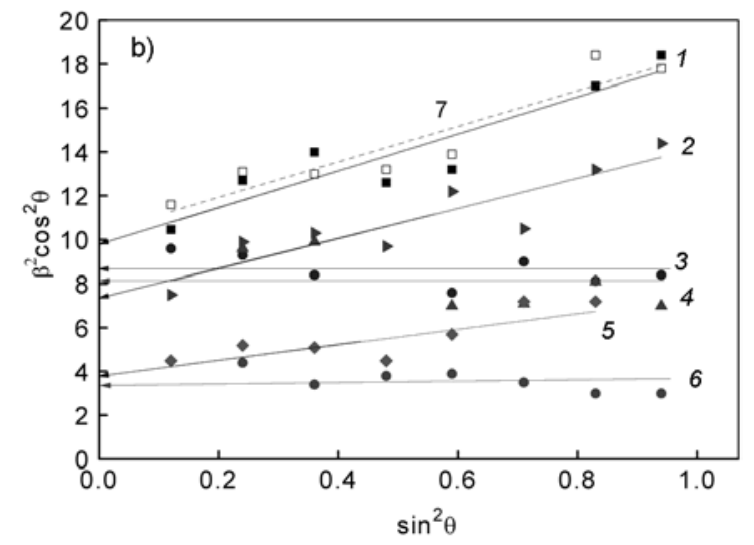

Fig. 2. Hall plots for a series of tungsten samples: 1 - WKB42; 2 - initial coating; 3 - DF-18; 4 - WKB30; 5 - WJL, 6 irradiated coating.

the basic contribution into the geometric broadening of diffraction maxima is substantial only at small diffraction angles; and the main contribution in it is caused by the receiving slit width and the profile of the radiation source (the projection of the focal spot). Additionally it should be noted that the influence of these functions is found to be the less, the wider is the initial convoluting line. As the diffraction angle (and, consequently, the line width) increases, the contribution of geometric broadening becomes lowered. For tungsten lines wider than mica ones even at low angles, the contribution of the geometric broadening is found to be small when using the receiving slit of $0.05 \mathrm{~mm}$, but with larger slits this is noticeable in the angle range of $\theta \leq 30^{\circ}$. As the measurements of the tungsten lines at low angles were carried out with the slit $0.1 \mathrm{~mm}$, we used the curve 2 in Fig. 1b for determination of the standard line width and calculations of physical broadening.

\subsection{Substructure parameters of tung- sten samples}

Hall plots for a series of the studied tungsten samples are shown in Fig. 2 for Gaussian approximation of diffraction line profiles. Originally we have chosen Gauss functions because the low angle reflections and especially standard ones had intense and sharp maxima.

From the Fig. 2 it is seen that all the plots are linear. Practically all the points of each plot lie on the straight lines. Absence of falling out points testifies the absence of packing defects. The straight lines do not get to the negative area. Testing on the correctness of geometric conditions and on the absence of calculation errors under conditions where the whole broadening is caused only by coherence length (CL) and microstrains is usually carried out using the expression $\cos \theta_{1} / \cos \theta_{2}<\beta_{2} / \beta_{1}<\operatorname{tg} \theta_{2} / \operatorname{tg} \theta_{1}[1$, 2 , 7]. Such testing has shown that the above condition is fulfilled for all of inclined plots, i.e. the measurements and calculations are correct. The shape of the plots indicates small coherence lengths and existence of micro-strains. For horizontal plots, the left part of the relation $\cos \theta_{1} / \cos \theta_{2} \approx \beta_{2} / \beta_{1}$ is realized; this indicates the absence of micro-strains. Here $\theta_{1}$ and $\theta_{2}$ are small and large diffraction angles; $\beta_{1}$ and $\beta_{2}$ are corresponding physical broadenings. For the double forged samples of the WKB series, the steepest is the plot 1 in Fig. 2; according to Gaussian approximations, the average coherence length is found to be $\langle L\rangle=50 \mathrm{~nm}$, while the average micro-strain level being $\left\langle\varepsilon>=1 \cdot 1 \cdot 10^{-3}\right.$. For the case of Cauchy approximation, these data are $\left\langle L>=150 \mathrm{~nm}\right.$ and $\left\langle\varepsilon>=0.9 \cdot 10^{-3}\right.$. As it is known, these data are limit values, while the reality being medial. Calculations fulfilled using harmonic analysis give the 
values $\langle L\rangle=130 \mathrm{~nm}$ and $\left\langle\varepsilon>=1.0 \cdot 10^{-3}\right.$. If the physical broadening is determined by the direct solution of the convolution equations by the regularization method, the following data are obtained: $\langle L\rangle=154 \mathrm{~nm}$ and $\left\langle\varepsilon>=0.5 \cdot 10^{-3}\right.$. From these data it follows, that the average micro-strains in this sample are about $1.0 \cdot 10^{-3}$ independently on the approximation method. The average $<L>$ is likely close to Cauchy approximation data near $140 \mathrm{~nm}$. In Fig. 2 the plot 7 (dashed line) corresponds to the sample 1, but the calculations were done using the spectral line width. This way of the calculation is also reasonable, because it does not affect the micro-strains values, while deviations by CL being in the limits of scattering.

The results of calculations using Gaussian approximation for CL, micro-strains, as well as dislocation density in the block walls, and chaotic dislocation density within the blocks are given in Table for all samples studied. We can not insist the data are absolutely true, but these reflect the variations from one type samples to another or within the same series of samples. Note, that even within the same series, the samples may have different substructure parameters. Additionally, it is seen that irradiation of a W-coating sample by hydrogen plasma in the regime of ( 5 fold pulsing by quasi-stationary plasma accelerator QSPA Kh-50 (National Science Center Kharkov Institute of Physics and Technology) plasma with heat load $0.6 \mathrm{MJ} / \mathrm{m}^{2}$ and duration of $0.25 \mathrm{~ms}$ for each pulse) results in annealing the dislocations both chaotically distributed over the coherence scattering areas in the bulk and at the boundaries.

We can state the fact that all the data obtained has the reasonable meaning and explanation. These do not contradict any theoretical conceptions. Consequently, the used approach to substructure investigation of quite perfect samples by the X-ray diffraction method is well applicable.

\section{Conclusions}

The technique of X-ray diffraction investigation of coherence length and microstrain level using approximation of diffraction line profiles by Gaussian and Cauchy functions as well as by harmonic analysis has been worked out for tungsten samples with quite perfect structure. The importance of right choice of a standard for obtaining the reasonable measurement results has been demonstrated. For the first approximation the possibility to use the spectral line width for calculation of the reflection true (physical) broadening has been shown. The contributions of basic instrumental factors into the reflection geometric broadening were estimated.

\section{References}

1. Ya.S.Umansky, Yu.A.Skakov, A.N.Ivanov, L.N.Rastorguyev, Crystallography, X-ray Diffraction and Electron Microscopy, Metallurgia, Moscow (1982) [in Russian].

2. S.S.Gorelik, Yu.A.Skakov, L.N.Rastorguyev, X-Ray Analysis and Electronographic Analysis, MISIS, Moscow (1994) [in Russian].

3. M.A.Krivoglaz, Diffraction of X-rays and Thermal Neutrons by Real Crystals, Naukova Dumka, Kiev (1983) [in Russian].

4. L.I.Gladkikh, S.V.Malykhin, A.T.Pugachov, M.V.Reshetnjak, Structure Analysis for Materials Physics, NTU "KhPI" Publ., Kharkov (2014) [in Russian].

5. A.I.Danilenko, A.V.Kurdyumov, V.F.Britun, Electron Microscopy and Strength of Materials. Ser.: Materials Physics, Structure and Properties of Materials, 15 (2008) [in Russian].

6. B.E.Warren, X-Ray Diffraction, Dover Publications, New York (1990).

7. Y.Z.Estrin, N.V.Isaev, T.V.Grigorova et al., Low Temper. Phys., 34, 665 (2008).

8. Y.Estrin, N.V.Isaev, S.V.Lubenets et al., Acta Mater., 54, 20 (2006).

9. A.M.Dovbnya, V.A.Mats, V.I.Sokolenko, Probl. Atom. Sci. and Techn., Ser.: Phys. Rad. Damage and Rad. Mater. Sci., No.5(81), 36 (2012).

10. V.A.Makhlaj, I.E.Garkusha, N.N.Aksenov et al., Phys. Scrip., T161, 014040 (2014).

11. I.E.Garkusha, S.V.Malykhin, V.A.Makhlaj et al., Techn. Phys., 84, 11 (2014).

12. T.Hirai, G.Pintsuk, J.Linke, M.Batilliot, $J$. Nucl. Mater., 390-391, 751 (2009).

13. M.Wirtz, J.Linke, G.Pintsuk et al., Phys. Scrip., T145, 014058 (2011).

14. M.A.Krivoglaz, Theory of X-Ray and Thermal Neutron Scattering by Real Crystals, Nauka, Moscow (1967) [in Russian].

15. D.M.Kheiker, L.S.Zevin, X-Ray Diffraction, Fizmatgiz, Moscow (1963) [in Russian]. 